\title{
Age-stage, two-sex life table analysis of Spodoptera frugiperda (JE Smith) (Lepidoptera: Noctuidae) reared on maize and kidney bean
}

Wen Xie, Junrui Zhi", Jiaqin Ye, Yeming Zhou, Cao Li, Yujian Liang, Wenbo Yue, Dingyin Li, Guang Zeng and Chaoxing $\mathrm{Hu}$

\begin{abstract}
Background: Spodoptera frugiperda (JE Smith), or fall armyworm, is one of major migratory agricultural pests with a wide range of hosts. The effect of different hosts (maize and kidney bean) on the growth and reproduction of $S$. frugiperda were investigated using the age-stage, two-sex life table method.

Results: The results showed that $S$. frugiperda could complete its entire life cycle on both hosts, albeit with significantly different development and reproduction. The durations of larval and pupal development were significantly prolonged whereas adult lifespan was shortened on kidney bean compared to maize. The differences of survival rates at each instar, prepupal and pupal stages between the two hosts were not statistically significant. The total preoviposition period was longer on kidney bean than that on maize (42.05 vs 39.04 days), but there was no difference in the oviposition rate (64.77 on kidney bean vs 62.48 on maize). The differences of net reproductive rate, intrinsic rate of increase and finite rate of increase were nonsignificant, while the mean generation time on kidney bean (42.05 days) was significantly longer than that on maize (40.92 days).
\end{abstract}

Conclusions: The results indicate that $S$. frugiperda can grow and reproduce normally on both hosts, although maize is more suitable. Nonetheless, the data show that this pest is harmful when the population density is high or when the preferred host is scarce.

Keywords: Spodoptera frugiperda, Life table, Maize, Kidney bean, Reproduction

\section{Background}

The fall armyworm Spodoptera frugiperda (JE Smith) (Lepidoptera: Noctuidae) is one of the important worldwide pests that is native to the tropical and subtropical Americas [1]. It was rated as one of the top 10 out of 1187 arthropod pests by the Centre for Agriculture and Biosciences International in the 2017 "State of the World's

*Correspondence: jrzhi@gzu.edu.cn

The Provincial Key Laboratory for Agricultural Pest Management

of the Mountainous Region, Institute of Entomology, Guizhou University, Guiyang 550025, Guizhou Province, China
Plants" report because of its perniciousness and invasiveness [2]. The inherently superior biological characteristics of S. frugiperda such as high fecundity, strong migratory ability, and wide range of hosts contribute to its invasiveness [3]. In the last 3 years, it has invaded 47 African countries, 18 Asian countries, and Australia [4]. Spodoptera frugiperda was first detected in Africa in January 2016 and rapidly spread to sub-Saharan Africa [5, 6]. Spodoptera frugiperda was first monitored in Jiangcheng County, Yunnan Province, in January 2019 and was reported as invasive species [7]. By December 31, 2019, 
S. frugiperda had spread to 1524 counties in 26 provinces in China [8].

Since S. frugiperda can feed on more than 350 plants of 76 families such as Gramineae, Compositae, and Leguminosae, it is more prone to outbreaks [9]. Two sympatric host-plant strains have been identified: the "maize $(\mathrm{C}-)$ strain" that mostly feeds on maize (Zea mays), cotton (Gossypium hirsutum), and sorghum (Sorghum bicolor), and the "rice (R-) strain" that is primarily associated with rice (Oryza sativa) and various pasture grasses [10]. The population of S. frugiperda that invaded China is thought to have originated as the offspring of a hybrid group of $\mathrm{R}$-strain female and C-strain male parents [11]. The nuclear genome of the $\mathrm{C}$-strain has occupied a dominant position in the long-term evolutionary process, which has led to the emergence of a unique $\mathrm{C}$-strain that has caused extensive damage to maize, sugarcane, sorghum [12]. In the absence of preferred hosts, the C-strain also feeds on other plants [13-15].

Kidney bean (Phaseolus vulgaris) is a host plant of the C-strain that is rich in nutrients [16]. China is one of the main producers of kidney bean, with the largest cultivation area, highest average yield and total output in the world [17]. Thus, S. frugiperda can cause considerable damage to kidney bean when there are no other suitable hosts. Clarifying the factors that influence the adaptation of pests to different hosts can provide insight into pest dynamics in the field, which can promote the timely adoption of prevention and control strategies [18].

This study aims to explore the suitability of $S$. frugiperda on kidney bean compared to maize (its preferred host) and determine whether the new C-strain of $S$. frugiperda has a potential damage risk on kidney bean. So, the development and reproduction of $S$. frugiperda on maize and kidney bean were compared using the agestage, two-sex life table method to assess the threat posed by the new C-strain to kidney bean production in China. Our results also provide a theoretical basis for investigating host adaptation mechanisms of S. frugiperda, which can guide future pest control strategies.

\section{Materials and methods Insect}

The original S. frugiperda colony was collected from maize in Guiyang, Guizhou, China, and transferred to a climate-controlled room (Temperature: $25{ }^{\circ} \mathrm{C} \pm 1{ }^{\circ} \mathrm{C}$, relative humidity: $70 \pm 5 \%$, light/dark cycle: $14: 10$-h, Ningbo Jiangnan Instrument Factory, Ningbo, China) in the laboratory, and were used to establish a laboratory colony. Fall armyworm larvae were reared on fresh maize leaves until the pupal stage while adults were fed with a $10 \%$ honey solution. All S. frugiperda stages were kept and isolated in plastic containers.

\section{Hosts}

Maize plants (Qingqing 300 variety; Guizhou Qinnongyuan Agricultural Development Co, Guiyang, China) were grown in a greenhouse under the above-described conditions at the Institute of Entomology, Guizhou University, China. Seeds were sown in pots (diameter of $12 \mathrm{~cm}$, height of $10 \mathrm{~cm}$ ) with nutrient soil and plants were watered once daily.

Kidney bean plants (Jinshulu variety; Shengnong Seed Company, Xinji, China) were planted in a climate chamber under the above-described conditions. The specific method refers to Liu et al. [19]. Healthy, undamaged kidney bean plants with two leaves were collected for experiments. No pesticides were applied to both crops and no pest damage was observed.

\section{Methods}

In order to evaluate the development and reproduction of S. frugiperda on different host plants, 20 adult couples (mated 3 days after emergence) were randomly selected from the laboratory population and placed in a $50 \mathrm{~cm} \times 50 \mathrm{~cm}$ cage, fed with a $10 \%$ honey solution. After $12 \mathrm{~h}$, all broods were collected and individual eggs were gently transferred with a brush to a 12-hole transparent storage box $(23 \times 15 \mathrm{~cm})$ with a small compartment $(5.5 \times 5 \mathrm{~cm})(10$ eggs were randomly placed into compartments per insect box, respectively) and each compartment was regarded as an independent space. Four 12-hole transparent storage boxes with fresh corn or kidney bean leaves were prepared for each host and three replicates per host were conducted. The developmental stage and survival from the first instar to adult was observed at 9:00 am daily. Fresh maize and kidney bean leaves were replaced daily. All boxes were kept separately in climate chamber under the abovedescribed conditions.

After pupation for 3 days, S. frugiperda was weighed and transferred to a round plastic box (upper and lower mouth diameters of 6 and $5 \mathrm{~cm}$, respectively, with a height of $3 \mathrm{~cm}$ ). After emergence, the adults fed with a $10 \%$ honey solution. S. frugiperda feeding on the same host was paired with one male and one female in a disposable plastic cup (upper and lower mouth diameters of 9.5 and $7.3 \mathrm{~cm}$, respectively, and with a height of $5.5 \mathrm{~cm}$ ) for observation and recording. The oviposition of female was accurately recorded every day until died. The egg stage of the offspring was observed every morning at 9:00 am and was replaced the egg stage of parent generation, and hatched larvae were fed to adulthood and the ratio of females was recorded. 


\section{Construction of the age-stage, two-sex life table}

According to the age-stage, two-sex life table principle $[20,21]$ and method [22-25], the following parameters were calculated and the age-stage, two-sex life tables of S. frugiperda on the two hosts were established:

1. Adult pre-oviposition period (APOP): the period between the emergence of an adult female until initiate of first oviposition. Total pre-oviposition period (TPOP): the time interval from birth to the beginning of oviposition) [26, 27].

2. Age-stage-specific survival rates $\left(S_{\mathrm{xj}}\right)$ : the probability that a newborn egg will survive to age $x$ and stage $j$ :

$$
S_{x j}=\frac{n_{x j}}{n_{01}} .
$$

3. Age-specific survival rate $\left(l_{\mathrm{x}}\right)$ : the probability that a newborn egg will survive to age $x$ :

$$
l_{x}=\sum_{j=1}^{m} S_{x j},
$$

where $m$ is the number of stages.

4. Age-stage-specific fecundity $\left(f_{x i}\right)$ : the number of hatched eggs produced by female adult at age $x$.

5. Age-specific fecundity $\left(m_{x}\right)$ : the number of eggs per individual at age $x$ :

$$
m_{x}=\frac{\sum_{j=1}^{m} S_{x j} f_{x j}}{\sum_{j=1}^{m} S_{x j}} .
$$

6. Age-specific maternity $\left(l_{x^{*}} m_{x}\right)$ : the product of $l_{x}$ and $m_{x}$.

7. Age-stage-specific life expectancy $\left(e_{x j}\right)$ : the time that an individual of age $x$ and stage $y$ is expected to live:

$$
e_{x j}=\sum_{j=1}^{m} \sum_{j=1}^{m} S_{i j}^{\prime},
$$

where $S_{i j}^{\prime}$ is the probability that an individual of age $x$ and stage $y$ will survive to age $i$ and stage $j$.

8. Age-stage-specific reproductive value $\left(V_{x j}\right)$ : the contribution of individuals of age $x$ and stage $y$ to the future population:

$$
v_{x j}=\frac{e^{-r(x+1)}}{S_{x j}} \sum_{i=x}^{n} e^{-r(i+1)} \sum_{j=y}^{m} S_{i j}^{\prime} f_{i j} .
$$

9. Intrinsic rate of increase $(r)$ :

$$
\sum_{x=0}^{\infty} e^{-r(x+1)} l_{x} m_{x}=1 .
$$

10. Finite rate of increase $(\lambda)$ :

$$
\lambda=e^{r} \text {. }
$$

11. Net reproductive rate $\left(R_{0}\right)$ :

$$
R_{0}=\sum_{x=0}^{\infty} l_{x} m_{x} .
$$

12. Mean generation time (T):

$$
T=\frac{\ln R_{0}}{r} .
$$

\section{Data analysis}

TWOSEX-MSChart 2020 software (http://140.120.197. 173/Ecology/prod02.htm) was used to calculate each parameter; the standard errors were determined by bootstrapping with 100,000 repetitions. Sigmaplot v12.5 software (Systat Software, San Jose, CA, USA) was used to plot the figures, and TWOSEX-MSChart software was used to evaluate the statistical significance of the observed differences. Differences between groups were evaluated by paired bootstrapping, with $P<0.05$ considered statistically significant; Student's $t$-value, degrees of freedom, eggs laid per female per day, pupal weight and survival rate (analyzed after arcsine square root transformation, formula: ARSIN(SQRT(A1*180/3.1415926)) at each stage before emergence were analyzed by SPSS version 22.0 (SPSS Inc., Chicago, IL, USA).

\section{Results}

\section{Development time of each stage of S. frugiperda}

The effect of host plants on the duration of each developmental stage of S. frugiperda is shown in Table 1. S. frugiperda could complete its entire life cycle on maize and kidney bean. The 1st, 2nd, 5th, and 6th instar larval and pupal stages were significantly longer on kidney bean compared to maize $(t=-7.782 ; p<0.01 ; t=-8.803$; $p<0.01 ; t=-11.824 ; p<0.01 ; t=-10.242 ; p<0.01$; respectively), and the total duration of the egg and larval stage was 22.56 days on kidney bean, which was significantly longer than 19.04 days on maize $(t=-13.397$; $P<0.01)$. However, adult longevity was significantly shorter on kidney bean than that on maize (females: 14.76 vs 16.15 days; males: 14.95 vs 16.25 days) ( $t=2.191$; $p<0.01 ; t=3.082 ; p=0.034$; respectively). The differences were nonsignificant in the duration of the 3rd and 4th instar larval and prepupal stages between two hosts $(t=1.59 ; p=0.114 ; t=0.176 ; p=0.860$; respectively). 
Table 1 Duration of each developmental stage of Spodoptera frugiperda on maize and kidney bean

\begin{tabular}{lcr}
\hline Duration, days & \multicolumn{2}{l}{ Hosts } \\
\cline { 2 - 3 } & \multicolumn{1}{l}{ Maize } & Kidney bean \\
\hline Egg & $3.40 \pm 0.06$ & $3.43 \pm 0.05$ \\
1st instar & $2.54 \pm 0.05^{*}$ & $3.15 \pm 0.06$ \\
2nd instar & $2.50 \pm 0.05^{*}$ & $3.19 \pm 0.06$ \\
3rd instar & $1.88 \pm 0.07$ & $1.74 \pm 0.06$ \\
4th instar & $2.50 \pm 0.06$ & $2.49 \pm 0.06$ \\
5th instar & $2.70 \pm 0.07^{*}$ & $3.96 \pm 0.08$ \\
6th instar & $3.57 \pm 0.07^{*}$ & $4.68 \pm 0.08$ \\
Egg +larva & $19.04 \pm 0.19^{*}$ & $22.56 \pm 0.22$ \\
Prepupa & $2.20 \pm 0.07$ & $2.13 \pm 0.06$ \\
Pupa & $12.04 \pm 0.10^{*}$ & $13.07 \pm 0.15$ \\
Female adult & $16.15 \pm 0.51^{*}$ & $14.76 \pm 0.36$ \\
Male adult & $16.25 \pm 0.38^{*}$ & $14.95 \pm 0.18$ \\
\hline
\end{tabular}

The data in the table are mean values $\pm \mathrm{SE}$

${ }^{*}$ Means $P<0.05$ (paired bootstrap test)

Table 2 Survival rate at each stage of Spodoptera frugiperda before emergence on maize and kidney bean

\begin{tabular}{lrr}
\hline Survival rate, \% & \multicolumn{2}{l}{ Hosts } \\
\cline { 2 - 3 } & \multicolumn{1}{l}{ Maize } & Kidney bean \\
\hline Egg & $100.00 \pm 0.00$ & $100.00 \pm 0.00$ \\
1st instar & $96.67 \pm 1.67$ & $95.00 \pm 2.89$ \\
2nd instar & $98.25 \pm 1.75$ & $91.26 \pm 2.28$ \\
3rd instar & $99.17 \pm 0.83$ & $98.09 \pm 0.83$ \\
4th instar & $94.76 \pm 1.42$ & $90.35 \pm 1.42$ \\
5th instar & $91.64 \pm 3.18$ & $90.23 \pm 1.77$ \\
6th instar & $96.05 \pm 2.59$ & $95.14 \pm 2.59$ \\
Prepupa & $97.85 \pm 1.08$ & $100.00 \pm 0.00$ \\
Pupa & $92.36 \pm 2.97$ & $95.00 \pm 1.08$ \\
\hline
\end{tabular}

The data in the table are mean values \pm SE

${ }^{*}$ Means $P<0.05$ (paired Student's $t$-test)

\section{Survival rate of S. frugiperda at each stage before emergence}

Survival rates at immature stages of S. frugiperda on the two hosts are shown in Table 2. The differences of survival rates at each instar, prepupal and pupal stages between the two hosts were not statistically significant.

\section{Reproduction and pupal weight}

APOP did not differ significantly between S. frugiperda adults fed maize and kidney bean (Table 3); however, TPOP was shorter for the former (39.04 vs 42.05 days) $(t=-3.556 ; p<0.01)$. There was no difference in the oviposition rate (OR) (64.77 on kidney bean vs 62.48
Table 3 Reproduction and pupal weight of Spodoptera frugiperda fed maize and kidney bean

\begin{tabular}{lll}
\hline Biological parameters & Hosts \\
\cline { 2 - 3 } & Maize & Kidney bean \\
\hline $\begin{array}{l}\text { Adult pre-oviposition period (APOP/ } \\
\text { day) }\end{array}$ & $6.69 \pm 0.52$ & $5.50 \pm 0.47$ \\
$\begin{array}{l}\text { Total pre-oviposition period (TPOP/ } \\
\text { day) }\end{array}$ & $39.04 \pm 0.59^{*}$ & $42.05 \pm 0.60$ \\
$\begin{array}{l}\text { Oviposition rate (OR) } \\
\text { Female ratio of offspring }\end{array}$ & $62.48 \pm 6.79$ & $64.77 \pm 6.03$ \\
Pupal weight (g) & 0.50 & 0.51 \\
\hline
\end{tabular}

The data in the table are mean values \pm SE

*Means $P<0.05$ (APOP and TPOP was paired by bootstrap test, oviposition rate and pupal weight was paired by Student's $t$-test)

Table 4 Population parameters of Spodoptera frugiperda fed maize and kidney bean

\begin{tabular}{lcc}
\hline Population parameters & \multicolumn{1}{l}{ Hosts } \\
\cline { 2 - 3 } & Maize & Kidney bean \\
\hline Net reproductive rate $\left(R_{0}\right)$ & $206.03 \pm 40.74$ & $172.38 \pm 36.73$ \\
Intrinsic rate of increase $(r /$ day $)$ & $0.13 \pm 0.01$ & $0.12 \pm 0.01$ \\
Finite rate of increase $(\lambda /$ day $)$ & $1.14 \pm 0.01$ & $1.13 \pm 0.01$ \\
Mean generation time $(T /$ day $)$ & $40.92 \pm 0.59^{*}$ & $42.05 \pm 0.60$ \\
\hline
\end{tabular}

The data in the table are mean values \pm SE

*Means $P<0.05$ (paired bootstrap test)

on maize) $(t=-0.248 ; p=0.805)$ and female ratio of offspring ( 0.50 on kidney bean vs 0.51 on maize). Additionally, the pupal weight of $S$. frugiperda on maze was significantly higher than that on kidney bean $(t=5.031$; $P<0.01)$.

\section{Population parameters}

The $r$ and $\lambda$ values of $S$. frugiperda populations were $>0$ and $>1$, respectively, for both maize and kidney bean (Table 4), indicating that the S. frugiperda were able to survive on the two hosts. The differences of $R_{0}, r$ and $\lambda$ were nonsignificant on the two hosts. On the other hand, $T$ was longer on kidney bean than that on maize (42.05 vs 40.92 days, $P<0.01)$.

\section{Survival rate}

$S_{x j}$ of $S$. frugiperda on maize and kidney bean are shown in Fig. 1. The values differed across developmental stages, which was attributable to variable growth rates among individuals. Spodoptera frugiperda completed the larval stage at 23 days and emerged at 29 days on maize compared to 28 and 33 days, respectively, on kidney bean. However, there were no differences in the survival of 

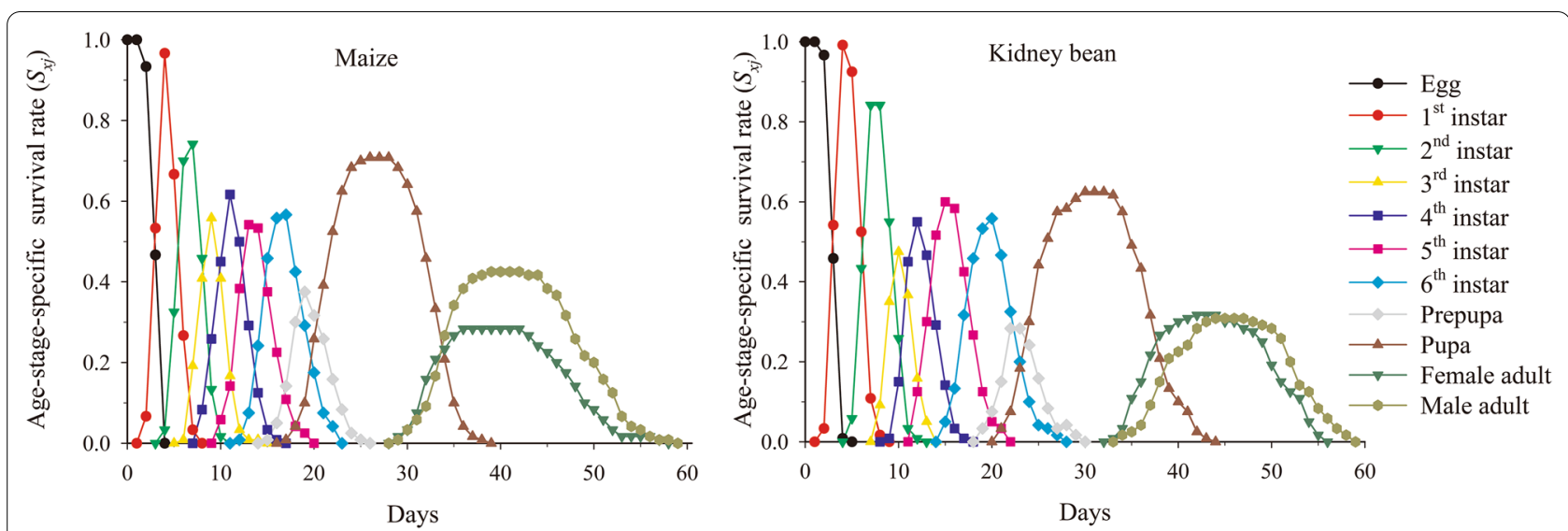

Fig. 1 Survival rate of Spodoptera frugiperda on maize and kidney bean. $S_{x j}$ : the probability that a newly laid egg will survive to age $x$ and stage $j$

adults between two hosts ( 59 days for both). This result suggested that it was significantly delayed for the development of $S$. frugiperda on kidney bean. The $S_{x j}$ of $S$. frugiperda males and females from egg to adult were 0.425 and 0.2833 , respectively, on maize, and 0.3083 and 0.3167 , respectively, on kidney bean, representing statistically significant differences according to the host for both sexes.

\section{Population survival rate and fecundity}

Figure 2 shows the influence of hosts on the survival rate and fecundity of S. frugiperda: $l_{x}, f_{x j}, m_{x}$, and $l_{x^{*}} m_{x}$. $l_{x}$ on maize and kidney bean showed a downward trend with increasing age; based on the estimated values, the death of the last adult on both hosts occurred at 59 days. $f_{x}, m_{x}$, and $l_{x}^{*} m_{x}$ reached maximum values at 41 days, on maize $(101.3235,40.5294$, and 28.7083 , respectively), and at 42 days on kidney bean plants
(72.4474, 36.7067 and 22.9417, respectively); each of these maxima were all lower compared to maize. Thus, a diet of maize was more conducive to the development and reproduction of $S$. frugiperda. Additionally, the fluctuations in the fecundity curve were suggest that the emergence and oviposition of S. frugiperda did not occur at specific ages.

\section{Life expectancy}

The value of $e_{x j}$ showed a downward trend on both maize and kidney bean, with maximum average longevity values of 39.5833 and 38.3 days, respectively, at age $0\left(e_{0,1}\right)$ (Fig. 3). The value of $e_{x j}$ was lower on kidney bean than on maize in the first 8 days but the trend was reversed thereafter, indicating that $S$. frugiperda developed more slowly on kidney bean.
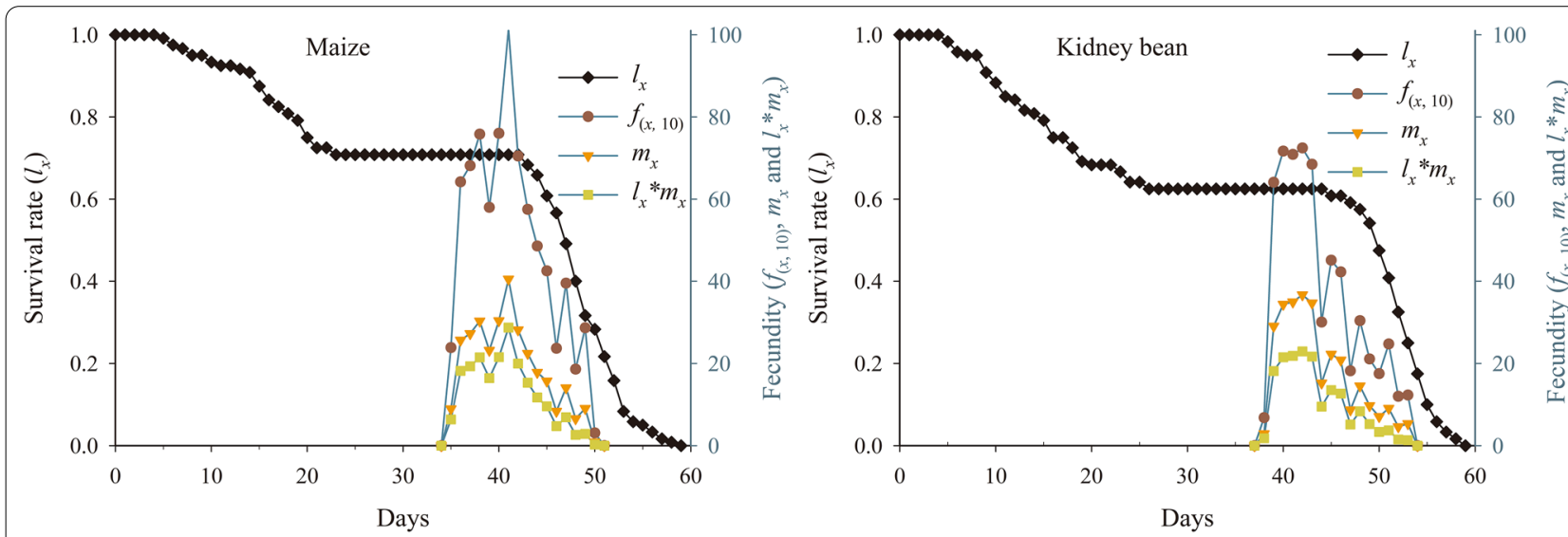

Fig. 2 Population survival rate and fecundity of Spodoptera frugiperda on maize and kidney bean. $I_{x}$ : the probability that a new egg will survive to age $x . f_{x j}$ : the number of eggs laid by a female adult at age $x$ and stage $j . m_{x}$ : the mean fecundity of individuals at age $x \cdot I_{x}{ }^{*} m_{x}$ : the product of $I_{x}$ and $m_{x^{\prime}}$ age-stage specific reproduction 

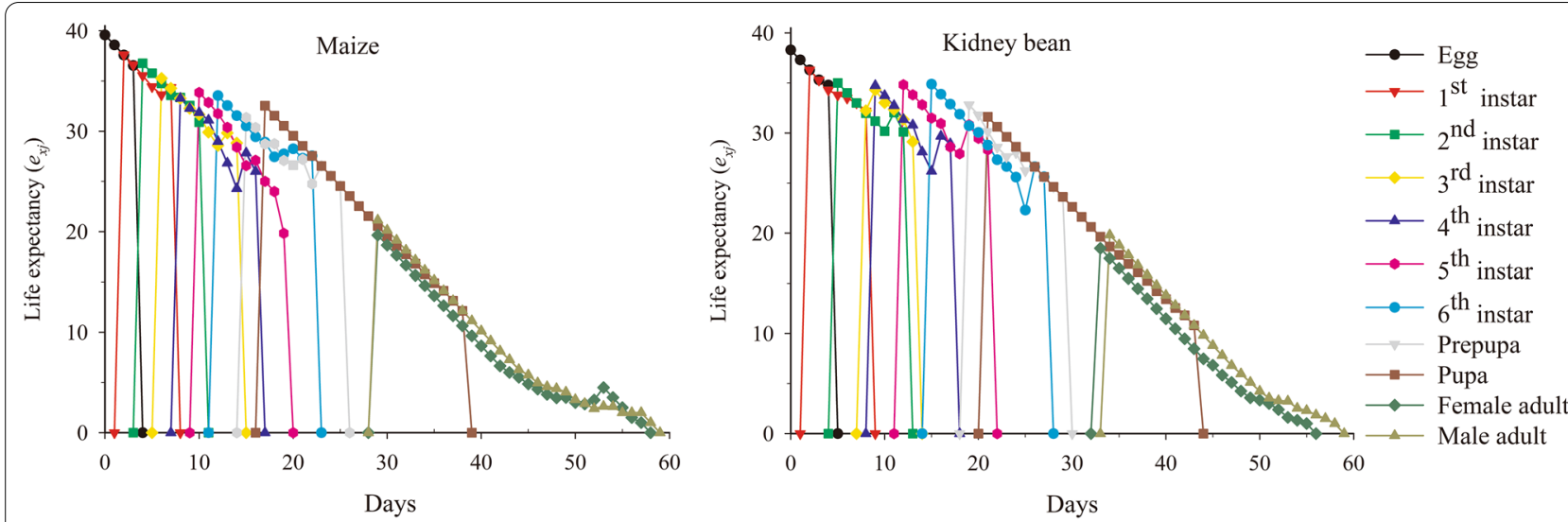

Fig. 3 Life expectancy of Spodoptera frugiperda on maize and kidney bean. $e_{x j}$ : the survival probability of an individual of age $x$ and stage $j$

\section{Reproduction value}

$v_{x j}$ of $S$. frugiperda feeding maize and kidney bean at age zero $\left(v_{0,1}\right)$ was 1.1392 and 1.1253 , respectively, which were both close to $\lambda$ (Fig. 4). The peak value of the $v_{x j}$ curve showed an upward trend with advancing age and developmental stage, with the highest value at 36 days on maize (412.9524) and at 39 days on kidney bean (360.6198). The highest $v_{x j}$ was in female adults reared on maize.

\section{Discussion}

The differences of nutrient content in host plants have big influence on the life cycle of herbivorous insects and affect the changing trend of their populations [26, 28-32], including those of S. frugiperda [33-36]. In this study, we found that the development and fecundity of $S$. frugiperda were affected by host species. The durations of larval and pupal stage were longer for S. frugiperda reared on kidney bean; moreover, adult longevity and fecundity were reduced compared to S. frugiperda fed maize.

The development of insects generally depends on the quality of the diet in the first few instars, which was different among the host [37]; a longer larva-to-adult period is thought to reflect a compensatory response in larvae to a low-quality diet [38]. Xu et al. [39] reported that the development time of the larval stage was prolonged and survival rate declined when $S$. frugiperda were fed tobacco (a non-preferred host) instead of maize, which was consistent with our findings. However, the final larval mortality rate on tobacco was $85.5 \%$, which was higher than the $32.5 \%$ that we observed on kidney bean. This might be attributable to differences in the principal materials or secondary metabolites in the leaves of the two plants [40].

The $r$ represents the growth potential of insect populations; a larger value reflects more rapid development [41, 42]. The differences of $R_{0}, r$ and $\lambda$ were nonsignificant on
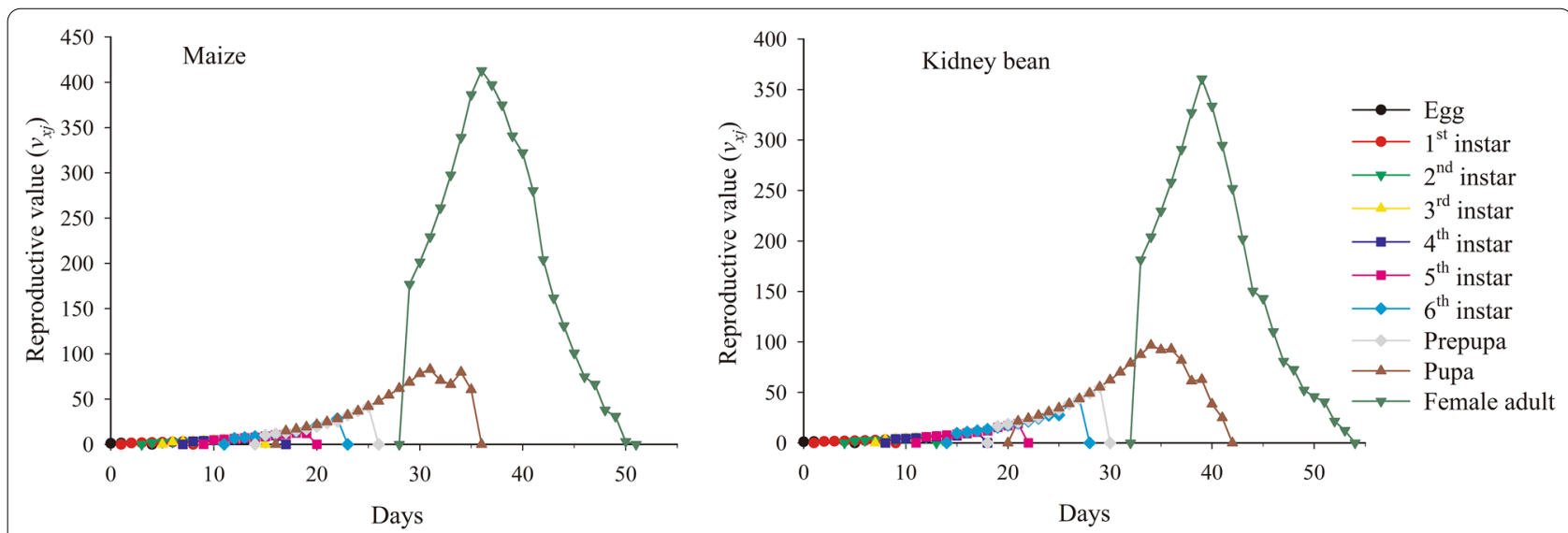

Fig. 4 Reproductive value of Spodoptera frugiperda on maize and kidney bean. $v_{x j}$ : the contribution of an individual of age $x$ and stage $j$ to future population growth 
the two hosts, whereas the value of $T$ was higher for $S$. frugiperda fed kidney bean compared to maize. Based on these parameters, maize was found to be more conducive to $S$. frugiperda growth and development than kidney bean. But other studies found that the population parameter values of $S$. frugiperda were lower on maize than on three triticeae crops [43], which may be related to diet quality and feeding conditions [38].

In addition, it was also found in this study that there were non-reproductive females on both host plants, and the ratio of non-reproductive females/total females was 8/34 (maize) and 16/38 (kidney bean). This phenomenon was most likely due to unsuccessful mating and were reported by other researchers $[44,45]$. But the mechanism of the generation of non-reproductive female and the increase in the number of non-reproductive female is still unclear, and further research is needed.

\section{Conclusion}

Although our results indicate that kidney bean is a less suitable host than maize, it still supported the full life cycle of $S$. frugiperda and is thus vulnerable to damage by this pest, especially if $S$. frugiperda populations optimize the utilization of kidney bean as a food source under conditions of high population density and food scarcity.

Therefore, the occurrence of S. frugiperda on crops should be closely monitored in the future. Additionally, clarifying the mechanisms and factors associated with adaptation to a kidney bean diet can provide a basis for predicting and controlling the growth of S. frugiperda populations.

\section{Acknowledgements}

The authors would like to thank Prof. Hsin Chi from National Chung Hsing University in Taiwan for providing the "age-stage, two-sex life table programme" software.

\section{Authors' contributions}

WX performed the experiments, analyzed data, and wrote the article. JRZ and CXH designed the experiments and revised the manuscript. QJY, DYL and GZ collected the original S. frugiperda colony and established a laboratory colony. YMZ analyzed data. WBY guided the use of Sigmaplot v12.5 software. CL and YJL assisted in planting the host. All the authors reviewed the manuscript.

\section{Funding}

This work was supported by The National Key Research and Development Program in China (No. 2019YFD0300100) and Guizhou International Science and Technology Cooperation Base (No. [2016] 5802).

\section{Availability of data and materials}

The datasets used and/or analyzed during the study are available from the corresponding author on reasonable request.

\section{Declarations}

Ethics approval and consent to participate Not applicable.

\section{Consent for publication}

The authors consent for publication.

\section{Competing interests}

The authors declare that the research has no competing interests.

Received: 8 May 2021 Accepted: 14 July 2021

Published online: 23 August 2021

\section{References}

1. Sparks AN. A Review of the biology of the fall armyworm. Fla Entomol. 1979:62(2):82-7.

2. Wild S. African countries mobilize to battle invasive caterpillar. Nat. 2017;543(7643):13-4.

3. Lu H, Tang JH, Lv BQ, et al. Recent advances in biological control and invasion risk of Spodoptera frugiperda. Chinese J Trop Crops. 2019;40(6):1237-44.

4. Wan J, Huang C, Li C, et al. Biology, invasion and management of the agricultural invader: fall armyworm, Spodoptera frugiperda (Lepidoptera: Noctuidae). J Integr Agric. 2020;19:2-19.

5. Day R, Abrahams P, Bateman M, et al. Fall armyworm: impacts and implications for Africa. Outlooks Pest Manage. 2017;28(5):196-201.

6. Goergen G, Kumar PL, Sankung SB, et al. First report of outbreaks of the fall armyworm Spodoptera frugiperda (J.E. Smith) (Lepidoptera, Noctuidae), a new alien invasive pest in west and central Africa. PLoS ONE. 2016;11(10):e0165632.

7. Jiang Y, Liu J, Xie M, et al. Observation on law of diffusion damage of Spodoptera frugiperda in China in 2019. Plant Prot. 2019;45(6):10-9.

8. $\mathrm{X} u \mathrm{YL}, \mathrm{Li} Z \mathrm{ZY}, \mathrm{Chen} \mathrm{J}$, et al. Assessment of potential economic loss of wheat industry caused by the fall armyworm Spodoptera frugiperda in China. J Plant Prot. 2020;47(4):740-6.

9. Montezano DG, Specht A, Sosa-Gómez DR, et al. Host plants of Spodoptera frugiperda (Lepidoptera: Noctuidae) in the Americas. Afr Entomol. 2018;26(2):286-300.

10. Nagoshi RN, Meagher RL. Behavior and distribution of the two fall armyworm host strains in Florida. Fla Entomol. 2004;87(4):440-9.

11. Zhang $L$, Liu $B$, Jiang $Y Y$, et al. Molecular characterization analysis of fall armyworm populations in China. Plant Prot. 2019;45(4):20-7.

12. Zhang YH, Zhang Z, Liu J, et al. Oviposition and feeding preference of Spodoptera frugiperda to gramineous weeds. Plant Prot. 2021;47(1):117-22+147

13. Pashley DP, Martin JA. Reproductive incompatibility between host strains of the fall armyworm (Lepidoptera: Noctuidae). Ann Entomol Soc Am. 1987;80(6):731-3.

14. Liu $Y Q$, Wang $X Q$, Zhong YW. Fall armyworm Spodoptera frugiperda feeding on cabbage in Zhejiang. Plant Prot. 2019;45(6):90-1.

15. Zhao M, Yang JG, Wang ZY, et al. Spodoptera frugiperda were found damaging potato in Shandong province. Plant Prot. 2019;45(6):84-6+97.

16. Kan L, Nie S, Hu JL, et al. Nutrients, phytochemicals and antioxidant activities of 26 kidney bean cultivars. Food Chem Toxicol. 2017;108:467-77.

17. Zhou J, Zhang H. Comparative analysis on international competitiveness of the world's leading exporter of edible beans. Food Nutr China. 2018:24(10):46-50.

18. Zhang TQ, Chen $Y X$, Zhang L, et al. Population dynamics of Loxostege sticticalis (Lepidoptera: Crambidae) on different host plants by using agestage two-sex life table. Plant Prot. 2020;46(1):101-7.

19. Liu L, Hou XL, Yue WB, et al. Response of protective enzymes in western flower thrips (Thysanoptera: Thripidae) to two Leguminous Plants. Environ Entomol. 2020;49(5):1191-7.

20. Chi H, Liu H. Two new methods for the study of insect population ecology. Bull Inst Zool Acad Sin. 1985;24(2):225-40.

21. Chi H. Life-table analysis incorporating both sexes and variable development rate among individuals. Environ Entomol. 1988;17:26-34.

22. Chi H, Su H. Age-stage, two-sex life tables of Aphidius gifuensis (Ashmead) (Hymenoptera: Braconidae) and its host Myzus persicae (Sulzer) (Homoptera: Aphididae) with mathematical proof of the relationship between female fecundity and the net reproductive rate. Environ Entomol. 2006;35(1):10-21.

23. Tuan SJ, Lee CC, Chi H. Population and damage projection of Spodoptera litura (F.) on peanuts (Arachis hypogaea L.) under different conditions using the age-stage, two-sex life table. Pest Manag Sci. 2014;70(5):805-13. 
24. Tuan SJ, Lee CC, Chi H. Population and damage projection of Spodoptera litura (F.) on peanuts (Arachis hypogaea L.) under different conditions using the age-stage, two-sex life table. Pest Manag Sci. 2014;70(5):1936.

25. Yang YT, Li WX, Xie W, et al. Development of Bradysia odoriphaga (Diptera: Sciaridae) as affected by humidity: an age-stage, two-sex, life-table study. Appl Entomol Zool. 2014;50(1):3-10.

26. Alami S, Naseri B, Golizadeh A, et al. Age-stage, two-sex life table of the tomato looper, Chrysodeixis chalcites (Lepidoptera: Noctuidae), on different bean cultivars. Arthropod Plant Interact. 2014;8(5):475-84.

27. Chi H, Fu JW, You MS. Age-stage, two-sex life table and its application in population ecology and integrated pest management. Acta Entomol Sin. 2019;62(2):255-62.

28. Sedighi L, Aghdam HR, Imani S, et al. Age-stage two-sex life table analysis of Sesamia nonagrioides (Lep: Noctuidae) reared on different host plants. Arch Phytopath Plant Protect. 2017;50(9-10):438-53.

29. Gharekhani GH, Salek-Ebrahimi H. Life table parameters of Tuta absoluta (Lepidoptera: Gelechiidae) on different varieties of tomato. J Econ Entomol. 2014;107(5):1765-70.

30. Yin WD, Qiu GS, Yan WT, et al. Age-stage two-sex life tables of Panonychus ulmi (Acari: Tetranychidae), on different apple varieties. J Econ Entomol. 2013;106(5):2118-25.

31. Nouri-Ganbalani G, Mardani-Talaee M, Haji-Ramezani MR. Age-stage, two-sex life history of the golden twin spot moth, Chrysodeixis chalcites (Lepidoptera: Noctuidae), on six commercial tomato cultivars under laboratory conditions. Can Entomol. 2015;148(1):92-101.

32. Umbanhowar J, Hastings A. The impact of resource limitation and the phenology of parasitoid attack on the duration of insect herbivore outbreaks. Theor Popul Biol. 2002;62(3):259-69.

33. Ribeiro LP, Klock ALS, Nesi CN, et al. Adaptability and comparative biology of fall armyworm on maize and perennial forage species and relation with chemical-bromatological composition. Neotrop Entomol. 2020;49(5):758-67.

34. Li DY, Zhi JR, Zhang T, et al. Effects of different host plants on the development and reproduction of Spodoptera frugiperda. J Environ Entomol. 2020;42(2):311-7
35. Guo JF, Zhang MD, Gao ZP, et al. Comparison of larval performance and oviposition preference of Spodoptera frugiperda among three host plants: potential risks to potato and tobacco crops. Insect Sci. 2020.

36. Wu Z, Shi P, Zeng Y, et al. Population life tables of Spodoptera frugiperda (Lepidoptera: Noctuidae) fed on three host plants. Plant Prot. 2019;45(6):59-64

37. Barros EM, Torres JB, Ruberson JR, et al. Development of Spodoptera frugiperda on different hosts and damage to reproductive structures in cotton. Entomol Exp Appl. 2010;137(3):237-45.

38. Silva DMD, Bueno ADF, Andrade K, et al. Biology and nutrition of Spodoptera frugiperda (Lepidoptera: Noctuidae) fed on different food sources. Sci Agric. 2017;74(1):18-31.

39. Xu PJ, Zhang DD, Wang J, et al. The host preference of Spodoptera frugiperda on maize and tobacco. Plant Prot. 2019;45(4):61-4+90.

40. War AR, Paulraj MG, Ahmad T, et al. Mechanisms of plant defense against insect herbivores. Plant Signaling Behav. 2012;7(10):1306-20.

41. Hu L, He Z, Zhang X. Age-stage two-sex life tables of the experimental population of Problepsis superans (Lepidoptera: Geometridae) on three Ligustrum species. Acta Entomol Sin. 2014;57(12):1408-17.

42. Qin JY, Zhang L, Chen $Y X$, et al. Age-stage two-sex life table for laboratory populations of oriental armyworm Mythimna separata (Walker) under different temperatures. J Plant Prot. 2017:44(5):729-36.

43. Tang Y, Guo JF, Tai HK, et al. Fitness of fall armyworm Spodoptera frugiperda reared on three triticeae crops. Plant Prot. 2020;46(5):77-83.

44. Zhou RQ, Feng L, Quan WL, et al. Mating behavior and its influencing factors in the striped stem borer, Chilo suppressalis (Walker). Huazhong Insect Res. 2013:9:33-40.

45. Moreau J, Thiéry D, Troussard JP, et al. Grape variety affects female but also male reproductive success in wild European grapevine moths. Ecol Entomol. 2007;32(6):747-53.

\section{Publisher's Note}

Springer Nature remains neutral with regard to jurisdictional claims in published maps and institutional affiliations.

\section{Submit your manuscript to a SpringerOpen ${ }^{\circ}$ journal and benefit from:}

- Convenient online submission

- Rigorous peer review

- Open access: articles freely available online

- High visibility within the field

- Retaining the copyright to your article

Submit your next manuscript at $\boldsymbol{\nabla}$ springeropen.com 